\title{
Yield and Cost Effects of Plot-Level Wheat Seed Rates and Seed Recycling Practices in the East Gojam Zone, Amhara Region, Ethiopia: Application of the Dose-Response Model
}

\author{
Yirgalem Eshete ${ }^{1, * \mathbb{D}}$, Bamlaku Alamirew ${ }^{2}$ and Zewdie Bishaw ${ }^{3}$ \\ 1 College of Agriculture and Natural Resource, Debre Markos University, Debre Markos P.O. Box 269, Ethiopia \\ 2 Yom Institute of Economic Development, Addis Ababa P.O. Box 62539, Ethiopia; bamlakalamirew@gmail.com \\ 3 International Center for Agricultural Research in the Dry Areas (ICARDA), Addis Ababa P.O. Box 5689, \\ Ethiopia; z.bishaw@cgiar.org \\ * Correspondence: etalem456@gmail.com; Tel.: +251-0913-655-606
}

check for updates

Citation: Eshete, Y.; Alamirew, B.; Bishaw, Z. Yield and Cost Effects of Plot-Level Wheat Seed Rates and Seed Recycling Practices in the East Gojam Zone, Amhara Region, Ethiopia: Application of the Dose-Response Model. Sustainability 2021, 13, 3793. https://doi.org/ $10.3390 /$ su13073793

Academic Editor: Shervin Hashemi

Received: 3 March 2021

Accepted: 24 March 2021

Published: 29 March 2021

Publisher's Note: MDPI stays neutral with regard to jurisdictional claims in published maps and institutional affiliations.

Copyright: (c) 2021 by the authors. Licensee MDPI, Basel, Switzerland. This article is an open access article distributed under the terms and conditions of the Creative Commons Attribution (CC BY) license (https:/ / creativecommons.org/licenses/by/ $4.0 /)$.

\begin{abstract}
Previous studies investigated the effects of seed rates and seed recycling practices on the yield and yield-related variables. However, higher yield does not always guarantee cost-efficiency. This study aimed to investigate the yield effects of plot-level seed rate and the cost-benefit analysis of seed recycling practices. This study has introduced the dose-response model to the existing analytical methods used in analyzing the effect of different agrochemicals on crop yield. A multistage stratified sampling technique was used to select a total of 450 sample respondents. Data were gathered using a mix of data collection tools. Descriptive statistics along with the dose-response model were applied for data analysis. Farmers of the study were found to be dissimilar in terms of their seed rate application. A dose-response analysis indicated that the highest average wheat yield was associated with a seed rate of $50 \mathrm{~kg} \mathrm{ha}^{-1}$ above what is recommended. The yield effect of seed recycling was also assessed, and a one-time seed recycling has caused a yield decline of $665 \mathrm{~kg} \mathrm{ha}^{-1}$ compared to the non-recycled seeds. The cost reduced using recycled seed is by far lower than the economic gains associated with using unrecycled and fresh seeds. The cost-benefit analysis made clear that farmers can reduce their seed costs through seed recycling, but their yields and net income can be best improved by using unrecycled certified bread wheat seed (CBWS). Thus, farmers must be encouraged to use unrecycled seed by establishing agricultural credit schemes geared towards seed procurement and seed price subsidy as key strategies to reduce economically wasteful seed recycling practices.
\end{abstract}

Keywords: wheat; seed rate; yield effect; dose-response; seed recycling; cost-benefit analysis

\section{Introduction}

Wheat productivity is substantially dependent on the use of crop genetics and the application of improved agronomic management practices. The role of quality seeds cannot be overemphasized in enhancing agricultural productivity and improving the livelihood of smallholder farmers [1,2]. Among other agronomic management practices, the seeding rate can be considered as one of the major factors determining the ability of the crop to capture the available resources and hence increase yield. In most cropping systems, seed rate is a factor under farmer's control and has remained to be a vital crop production factor and one of the best decisions required to be made. However, the optimum seed rate for maximum bread wheat production greatly varies between regions according to climatic conditions, soil types, sowing time, cultivars, spacing, and other agronomic practices [3].

The majority of farmers in the developing countries are using either below or above the optimum recommended seed rates causing a wider yield gap between the potential and the actual production. In Ethiopia, despite the need for optimum wheat seed rates disaggregated on spatial, temporal, and varietal levels, seed rate recommendations are 
still based on blanket recommendations of a "one-size-fits-all" approach. Moreover, the contribution of certified seed in boosting productivity and enhancing the livelihood of farmers can be realized if seeds are not recycled or are replaced by new seeds based on expected utility. The expected productivity gains concomitant with the use of certified seeds of improved varieties are likely to be lost over time as the genetic merits conferred by breeding will break down and make resource-poor smallholder farmers vulnerable to risks associated with biotic and abiotic stresses. The use of improved certified seeds without a parallel adoption in other agronomic practices, such as seed rates, seed replacement, spacing, and tillage, did not bring a substantial increase in bread wheat productivity [4]. Yet, information on the yield effect of different agronomic practices is meager. Especially, there is inadequate information about the yield effect of farmer's plot level bread wheat seed rates and seed recycling practices in the study area. Thus, investigating wheat yield response to different plot level seed rates and seed recycling practices has been the major objective of this study. The output in this study will help farmers to decide whether they can reduce their costs of seed by correcting the seed rate. Moreover, the use of different seed rates and seed recycling practices are often evaluated in terms of one indicator, usually yield gains. However, the use of different seed rates and seed recycling practices should be evaluated from multiple dimensions. This study is thus meant to investigate the yield effects of plot-level seed rates along with the cost-benefit analysis of using recycled and unrecycled seeds. The cost-benefit analysis is expected to help farmers decide if they can reduce their seed cost through seed recycling and if their yields can be improved by using unrecycled certified bread wheat seed (CBWS) as compared to recycled seeds.

This research is expected to contribute to the literature in the following three ways. First, it will introduce a different analytical approach in its effort to investigate the yield effect of plot-level seed rates. Previous studies measured the yield effect of seed rate simply as the amount of crop yield per hectare in response to a specified seed rate, while others employ linear regression method and average treatment effect models $[3,5,6]$. In this study, the dose-response model is applied. It is a common analytical method in medical sciences $[7,8]$. To the researcher's knowledge, this paper is the first to use the generalized linear dose-response model to investigate the yield effect of plot-level seed rates in the study area. Second, it will add to the empirical literature on the yield effect of plot-level seed rates $[5,9]$. Third, this study analyzed the yield effect of seed rates of recycled and unrecycled CBWSs along with the cost-benefit analysis of seed recycling. Therefore, the output in this study will also help farmers to decide whether they can reduce their costs by recycling seeds or not.

\section{Research Methods}

\subsection{Description of the Study Area}

East Gojam zone has a total of 17 districts. Its headquarters, Debre Markos, is located 300 and $260 \mathrm{~km}$, far from Addis Ababa (the capital city of the country) and Bahir Dar (the capital city of the region), respectively. It is located at $10^{\circ} 19^{\prime} 0.00^{\prime \prime}$ North and $38^{\circ} 00^{\prime} 0.00^{\prime \prime}$ East. The mixed farming system is the main occupation of farmers in the East Gojam zone. The area is dominated by mixed agricultural systems [10]. Figure 1 below indicates the map of the study areas. 


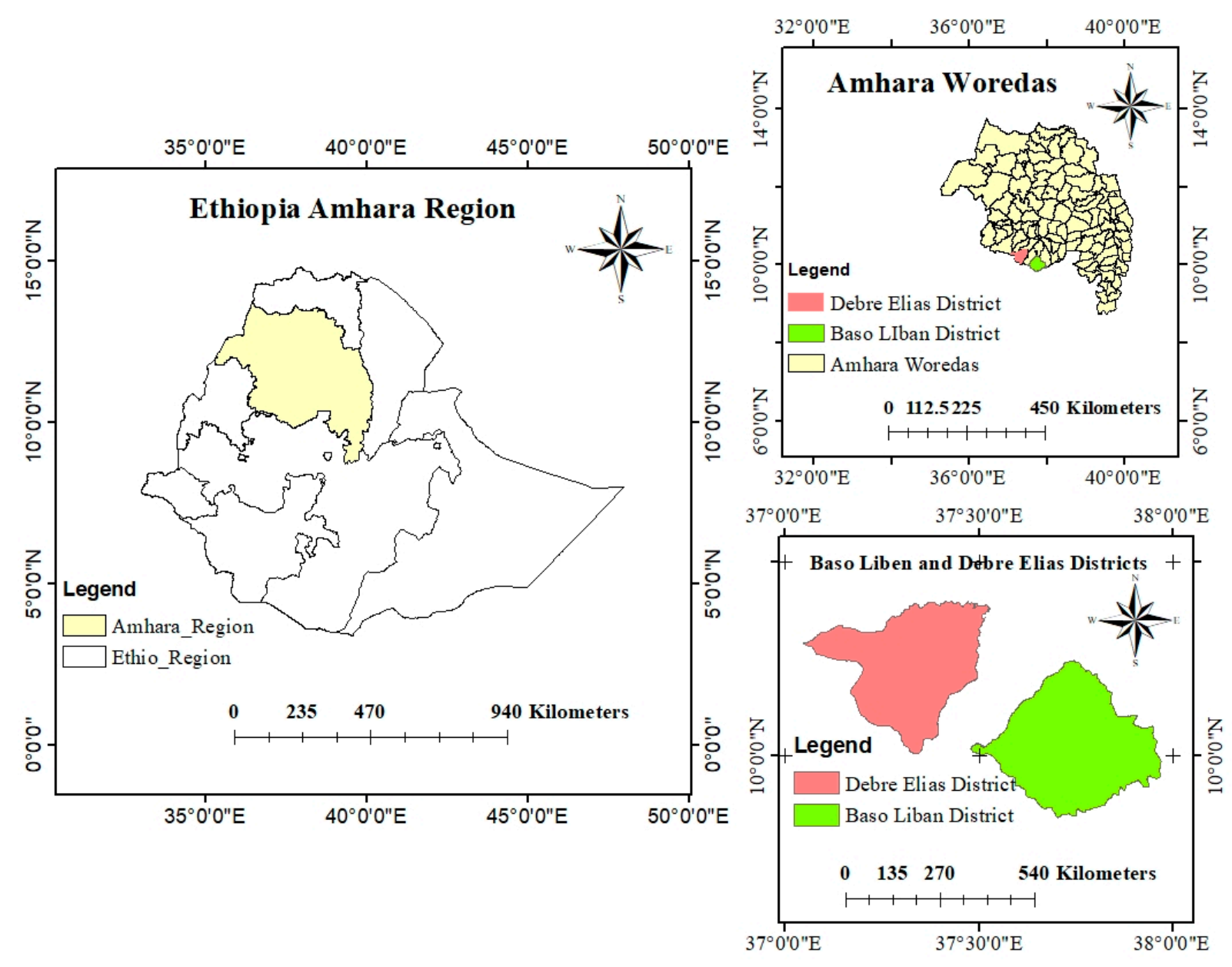

Figure 1. Map of the study area.

\subsection{Sampling Technique and Sample Size Determination}

Multi-stage purposive and random sampling methods together with probability proportional to size (PPS) were employed in the selection of sample study areas. In the first stage, the East Gojam Zone of the Amhara National Regional State (ANRS) was purposefully considered due to its high potential for wheat production. In the second stage, Baso Liban and Debre Elias districts were considered as specific study areas. The potential for wheat production, availability of sufficient representative sample respondents, and the long year's acquaintance of the study places by the researcher were a few of the reasons to consider these districts. Debre Elias and Baso Liban districts have 15 and 22 kebeles (Kebele is an Amharic term that refers to the lowest administrative region), respectively. Given the financial, time, and other resource constraints, this study has considered a total of 8 rural kebeles. These eight kebeles are thought to be sufficient and representative as there is homogeneity between most of the kebeles in terms of their agronomic practices in wheat production. Then 3 and 5 kebeles were considered as specific study areas by using the PPS sampling technique. A total of 450 farmers, determined by [11] sample size determination formula, was considered for the study.

\subsection{Data Collection Methods}

This study employs both primary and secondary data sources. However, it has heavily relied on primary data sources, including smallholder farmers involved in wheat production, development agents, crop experts, and key informants. Moreover, the information gathered from these primary sources was supported and triangulated from available secondary data sources, including regional and district annual reports, research findings, 
journals, publications, thesis, dissertations, books, proceedings, and so forth. Both qualitative and quantitative data types were gathered using structured interview schedules, questionnaires, FGDs (Focus Group Discussions), KIIs, (Key Informant Interviews), and personal observations.

\subsection{Data Analysis Methods}

\subsubsection{Descriptive Data Analysis Tools}

Both measures of central tendency (mean, median, and mode) and measures of central dispersion (range, variance, and standard deviation) were frequently used.

\subsubsection{Specification of Dose-Response Model}

Dose-response models are regression models where the explanatory variable is usually referred to as the dose or concentration, while the dependent variable is usually referred to as response or effect. A dose was also known as "metameter", is defined as any pre-specified amount of biological, chemical, or radiation stress eliciting a certain, well-defined response. Other kinds of exposure or stress could also be imagined, e.g., the time elapsed in germination experiments. The dose is a non-negative quantity, and it is often, but not always, assumed to be measured without error, as is often the case in designed experiments [7]. In this study, the seed rate applied by the farmers will be considered as the dose or the concentration, while the amount of wheat yield is going to be considered as response or effect.

There are various types of dose-response models. Specifically, responses are defined to a given dose as the quantification of a biologically relevant effect, and as such, it is subject to random variation. The most common type is a continuous response, such as biomass, enzyme activity, or optical density. A binary or aggregated binary (binomial) response is also frequently used to describe results, such as dead/alive, immobile/mobile. The response may also be discrete as in the number of events observed in a specific time interval, such as the number of juveniles, offspring, or roots. Dose-response curves may also be used to summarize experiments where the response is an event time that is the time elapsed before some specific event is being observed absent [8]. This study will undertake a linear dose-response regression between wheat seed rates (dose/concentration) and wheat yield (response/effect).

The full specification of a statistical dose-response (regression) model involves specifying how the mean is described by a parametric function of dose as well as specifying assumptions about the distribution of the response. We will focus on ways to model the mean trends through mostly S-shaped or related biphasic functions because these functions have in common that they reflect a basic understanding of the causal relationship between the dose and the response, e.g., when a dose increases, the response monotonically decreases or increases one-way or another towards minimum or maximum response limits, respectively. Consequently, these functions have turned out to be extremely versatile for describing various biological mechanisms involving model parameters that allow the interpretation of observed effects within a biologically plausible framework. So we define dose-response models to be a collection of statistical models having a certain mean structure in common; this is not a strict mathematical definition, but rather a definition driven by applications. Consequently, dose-response models encompass a range of statistical models from nonlinear regression, generalized (non) linear regression, and parametric survival analysis. Let y denote an observed response value, possibly aggregated in some way, corresponding to a dose value $x \geq 0$. The values of $y$ are often positive but may take arbitrary positive or negative values. Furthermore, we will assume that observation of $y$ is subject to sampling variation, necessitating the specification of a statistical model describing the random variation. Specifically, we will focus on characterizing the mean of $\mathrm{y}$ (denoted $\mathrm{E}(\mathrm{y})$ below) in terms of a model function $\mathrm{f}$ that depends on the dose $\mathrm{x}$ :

$$
E(y)=f\left(x, \beta_{0}\right)
$$


So, for a given dose $x$, the corresponding observed response values will be distributed around $f(x, \beta)$. The function $f$ is completely known as it reflects the assumed relationship between $x$ and $y$, except for the values of the model parameters $\beta=(\beta 1, \beta p)$, which will be estimated from the data to obtain the best-fitting function. The remaining distributional assumptions on y will depend on the type of response. For instance, for a continuous response, the normal distribution is commonly assumed, whereas, for a binary response, the binomial distribution is commonly assumed.

\section{Result and Discussion}

\subsection{Bread Wheat Seed Sources}

Several bread wheat varieties have been recommended for highland (Dega) and midhighland (Weyina-Dega) agro-ecological zones of the country. Ogolcho (ETBW5520), Kubsa, Danda'a, Kakaba, Digalu, Tay, Katar, Abola, Dereselegn, K6290 Bulk, K6295-4A, ET-13 A2, Pavon 76, Dashen, Mitike, Galema (HAR-604), Tusa, Tura, Katar, Shina, Simba, Guna, and Densa have been introduced in both study districts [12].

However, almost all farmers have already abandoned using them except Ogolcho (ETBW5520), released in 2012, and it has become an exclusive wheat variety being grown in the study areas during the production season considered in this study. Several agricultural experiments and trials are carried out in the study area by different academic and research institutes and other governmental and non-governmental organizations. Despite these efforts, farmers in the study area are unable to access several alternative wheat varieties during the production season. Farmer's access to seed is quite supply-driven that the major formal source for CBWS (largely the Amhara Seed Enterprise) does not usually supply more than one variety during a specific production season. As a result, farmers are compelled to stick to a single variety supplied to them. Furthermore, [13] seemed to give a similar impression of low spatial diversity of wheat varieties where only a few dominant varieties appeared to occupy a large proportion of the wheat area. Although varietal diversity is low, the use of certified seed has been exceptionally high as compared to findings in several studies [13-15]. This may be because farmers are benefited from the spillover effects of research efforts being undertaken by several governmental and NonGovernmental Organizations. This may have encouraged farmers to allocate larger plots for wheat production using certified seeds. Given its huge potential for wheat production, farmers of the study area are often preferred targets for seed multiplication for the regional and national seed enterprises. This has allowed farmers to have easy and timely access to certified seeds, which could be one important reason for exceptionally high certified bread wheat seed use. Moreover, farmers' long years of experience and perceived benefits in using certified seeds could be another explanation for high rates of certified seed use. The spread effect of agricultural research to large-scale application of farm innovation is witnessed in other studies, too $[16,17]$.

Farmers in the study area acquire seeds from four important sources (Appendix A Table A3). The Amhara Seed Enterprise has been a dominant seed supplier for almost $73 \%$ of the farmers, followed by farmer's cooperatives that supply seed for over $15 \%$ of the farmers. Farmers of the study area participate in seed multiplication. Yet, these farmers cannot sell seeds by themselves but through the cooperative to which they belong once the seed is approved and certified. Zonal and district experts working in the seed quality department will control the quality of seeds produced by the farmers, whereas the Ethiopian and the Amhara Seed Enterprises provide the technical support for seed production. Farmer's own saved seeds, along with research and academic institutions, have also been important seed sources for few sections of the farming community in the study area.

\subsection{Yield Effects of Plot-Level Seed Rates}

Among others, an appropriate plant population determined by seed rates is one of the most important agronomic practices for optimizing wheat yield by reducing competition 
for minerals $[1,10,18]$. Yet, wheat yield response to seed rate is inconsistent across spatial and temporal bases due to several biotic and abiotic factors. Ceteris paribus seed rate is an important yield determinant in bread wheat production. A better understanding of the relationship between seed rates and yield in wheat production could have paramount importance in improving seeding rate recommendations according to specific spatial, temporal, and bread wheat variety-related characteristics [5,9]. The application of the best quality seed may lead to lower gains if the recommended seed rates are not applied [14,19].

The Ministry of Agriculture generally recommends a seed rate of $80-100 \mathrm{~kg}$ of seed per hectare. However, based on location-specific wheat variety trials conducted in the East Gojam zone, a seed rate of $100-150 \mathrm{~kg} \mathrm{ha}^{-1}$ is recommended for Baso Liban and Debre Elias districts. However, farmers in the study area do not stick to the recommendation and use their own seed rates. The yield and yield effects of seed rates of the CBWS of the Ogolcho variety were evaluated when it was introduced in 2012 in the selected farmer training centers (FTCs) in Basoliban and Debre Elias districts. Since then, the yield effect of farmer's own plot level seed rates has never been empirically assessed. Therefore, exploring the effect of the plot level seed rates on wheat yield is an important objective of this study. Respondent farmers are classified into three groups for the study. The 1st category (below-recommended seed rate group) includes farmers with a seed rate ranging from $50-99 \mathrm{~kg} \mathrm{ha}^{-1}$ (50 kg ha ${ }^{-1}$ being the lowest observed seeding rate). The 2 nd group (recommended seed rate users group) includes respondents with a seed rate ranging between 100 and $150 \mathrm{~kg} \mathrm{ha}^{-1}$. The 3rd group ("above recommended") constitutes farmers with a seeding rate greater than $150 \mathrm{~kg} \mathrm{ha}^{-1}$.

The survey results showed that about $4.9 \%, 48 \%$ and $47.1 \%$ of the respondents use seed rates below, above, and within the recommended seed rates, respectively (Table 1). This means that above $95 \%$ of the farmers in the study area use seed rates either above the recommendation or within the recommended seed rate range. On average, farmers of the study area have used a seed rate of $194.4 \mathrm{~kg}^{-1}$, which is higher than what is recommended. A similar finding was reported by [12], where they had reported an average seed rate of $264.56 \mathrm{~kg} \mathrm{ha}^{-1}$, about $100 \mathrm{~kg}$ above what is recommended. Several studies also found the use of higher seed rates. Late seeding dates, planting methods, the need to compensate for possible damages due to ants, rats, and birds, intentions of grain yield maximization, and weed control are reported as some of the reasons for higher seed rates $[3,20]$. These explanations for higher seed could also be adopted as reasons for the higher seed rates witnessed in this study. The Pearson's correlation indicates a negative nexus between seed rate and hand weeding frequency $(r=-0.5248, p=0.05)$. This could be interpreted as that farmers reduce the seed rate for making frequent hand weeding easy and convenient. Moreover, farmers in the study area have reportedly used lower seed rates due to perceived high seed prices and insufficient supply of certified seeds. Though it is not witnessed from the findings of this study, studies indicated several reasons that push farmers to use seed rates below what is recommended. For instance, superior agronomic practices, such as row planting and transplanting, reduce the seed rate required in crop production. These practices do not only reduce seed rates but also allow more spacing between seedlings, permit easy weeding, reduce competition between seedlings and allow for better branching out (tillering) of crops $[6,21]$.

A good section of the respondents (48\%) has used a seed rate above the recommendation. The Pearson's correlation indicates a positive nexus between the frequency of seed recycling and the amount of seed rate $(\mathrm{r}=0.5534, p=0.05)$. This implies that higher seed rates are associated with the frequency of seed recycling. The recycled seeds are cheaper than fresh and unrecycled CBWS that may encourage farmers to purchase and use more amounts of bread wheat seed. Several studies provided explanations as to why farmers use more seed rates. For instance, quite often, late seeding dates cause higher seeding rates because a delay in sowing normally reduces individual plant growth and tiller production [20]. The result in this study does not portray a significant yield difference between farmers who use recommended and below recommended seed rates. The lowest 
average wheat productivity was associated with the farmers, who apply seed rates above what is recommended.

Table 1. Distribution of average productivity across varying seed rates.

\begin{tabular}{cccccc}
\hline \multirow{2}{*}{ Seed Rate Group } & \multirow{2}{*}{ Obs. } & \multicolumn{2}{c}{ Seed Rate (kg ha ${ }^{-1}$ ) } & \multicolumn{2}{c}{ Productivity (Qt ha $^{-\mathbf{1})}$} \\
\cline { 3 - 6 } & & Mean & Std. Dev & Mean & Std. Dev. \\
\hline Below Recommended & $22(4.9)$ & 67.0455 & 11.9183 & 40.3636 & 3.8365 \\
Recommended & $212(47.1)$ & 133.9623 & 21.2714 & 40.3726 & 3.80499 \\
Above Recommended & $216(48)$ & 266.6667 & 93.3859 & 36.7361 & 38.62667 \\
\hline Total & $450(100)$ & 194.3889 & 97.0926 & 5.7883 \\
\hline
\end{tabular}

Respondents of the study were asked about the reasons for the higher seed rate they are applying. Expected better yield gains associated with higher seed rates have been the most frequently reported reason for higher seed rates. The practice of using higher seed rates was reported in other studies as well $[19,20,22,23]$. These studies unfold that farmers usually use higher seed rates than what is recommended due to land scarcity, availability of credit markets for agricultural inputs, and access to markets. Though not implied from the data gathered here, these same reasons could also explain the findings in this study. Similarly, farmers in least developed countries (LDCs) prefer to use higher seed rates beyond what is recommended hoping that it will be a good strategy to control weeds and help them in coping with risks of crop production. High seed rate application beyond what is recommended is discouraged due to the negative consequences on seed quality, such as seed size and weight $[19,24]$.

One cannot have a clear picture of the yield effects of seed rate from the descriptive statistics presented above. The best analytical model to understand the effect of a dose (concentration) on response is the dose-response function based on the generalized linear regression model. This regression model produces such estimates more quickly. However, the use of post estimation command, such as margins plot in STATA (StataCorp, TX, USA), enables to paint a clear picture of the effect of a dose (seed here) on the response (wheat yield per hectare). To do so, the data gathered was arranged in six seed rate groups to include all observations within $\pm 50 \mathrm{~kg} \mathrm{ha}^{-1}$ of the recommended seed rates. All farmers that apply a seed rate of $50 \mathrm{~kg} \mathrm{ha}^{-1}$ or below are categorized as the 1st group, and the seed rate is calibrated as $50 \mathrm{~kg} \mathrm{ha}^{-1}$ ( $50 \mathrm{~kg} \mathrm{ha}^{-1}$ being the lowest seed rate). The seed rates above $50-100$ are calibrated as 100 , while seed rates above 100-150, above 150-200, above 200-250, above 250-300, and above 300 were calibrated as 150, 200, 250 and $300 \mathrm{~kg} \mathrm{ha}^{-1}$, respectively. The regression coefficient is calculated using the generalized linear model to investigate the effect of the seed rate applied by farmers on wheat productivity. The result indicated that a $1 \mathrm{~kg}$ increase in seed rate is associated with a probability of 0.054 increases in wheat productivity (See Appendix A Table A1). To sum up, Figure 2 below shows the relationship between plot level seed rate and yield in the study area.

Further analysis was carried out using predictive margins at the mean to investigate the magnitude of change in wheat productivity when the seed rate applied by the sample respondents increases from $50 \mathrm{~kg} \mathrm{ha}^{-1}$ (the minimum seed rate reported) to $300 \mathrm{~kg} \mathrm{ha}^{-1}$ (the maximum seed rate applied). Results of the analysis depicted that seed rates below what is recommended were associated with lower wheat productivity. Interestingly, a seed rate of $200 \mathrm{~kg} \mathrm{ha}^{-1}$ is associated with the highest average wheat production per hectare (4225 kg ha ${ }^{-1}$ ). This means that an extra $50 \mathrm{~kg} \mathrm{ha}^{-1}$ application beyond the recommended seed rate is associated with higher productivity. This suggests that there might be a need to revise the seed rate recommendation for the study area. As presented in Table 2, an increase in the successive seed rate from $50-200 \mathrm{~kg} \mathrm{ha}^{-1}$ was associated with an increase in wheat productivity. However, additional seed rates being applied beyond $200 \mathrm{~kg} \mathrm{ha}^{-1} \mathrm{did}$ not show an increasing effect on wheat productivity. Rather, productivity started to decline after the $200 \mathrm{~kg} \mathrm{ha}^{-1}$. Though the recommended seed rate in the study area was between 
100 and $150 \mathrm{~kg} \mathrm{ha}^{-1}$, higher yield gains were reported for seed rates from 150-200 kg ha ${ }^{-1}$ This is in agreement with other field-level experiments and surveys results by different authors that reported increasing the seed rate of wheat from 100-200 $\mathrm{kg} \mathrm{ha}^{-1}$ increased the grain yield and straw yields [21,24]. This study found that about $48 \%$ of the respondents reportedly used higher seed rates than what is recommended. Yet, the seed rate is best when it is associated with the maximum grain yield. The economic theory of diminishing return to input was proved from the findings of this study. The wheat yield hardly changes with additional units of seed rates once the maximum yield level was achieved. This could be witnessed from the flatten curve after $200 \mathrm{~kg} \mathrm{ha}^{-1}$ seed rates in Figure 1 above. Seed rates used above what is required to reach the flat part of the curve is money wasted that could have been used for other development expenditures.

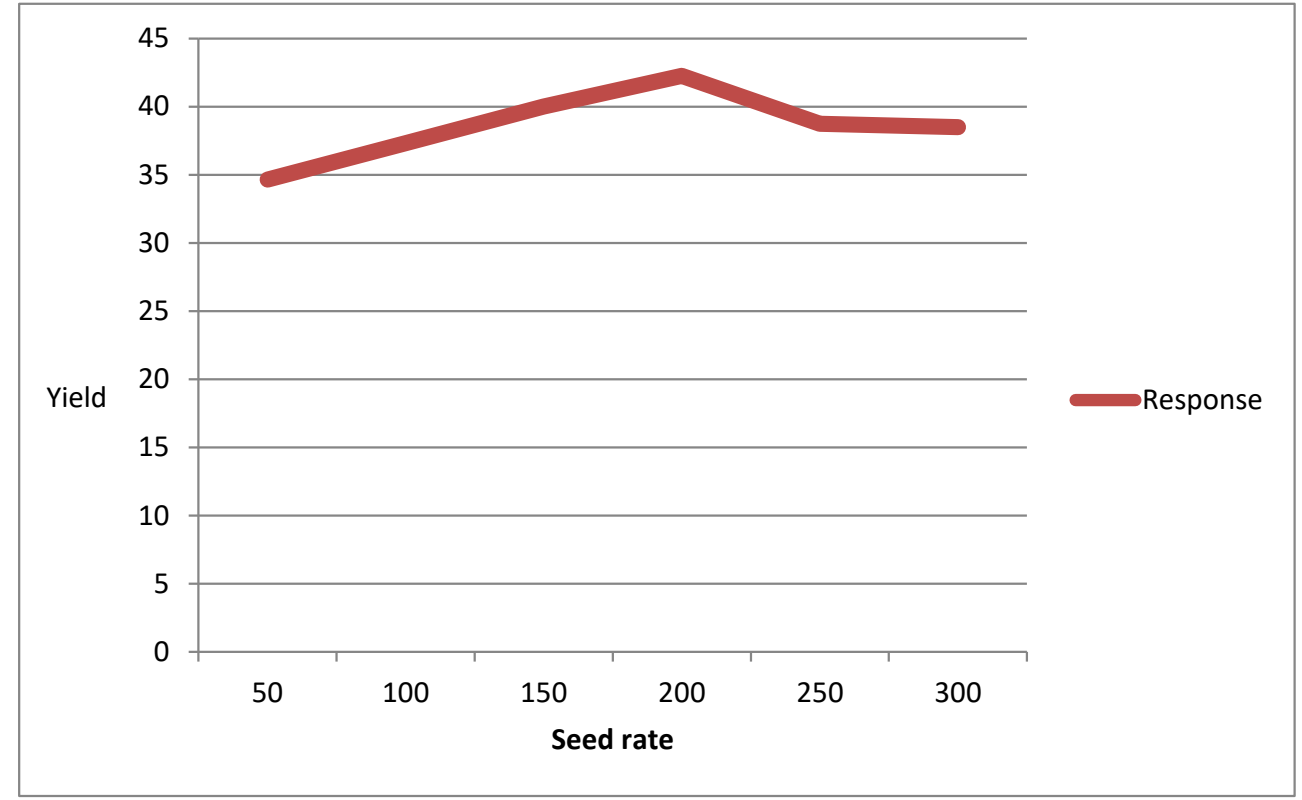

Figure 2. Seed rate-yield response curve.

Table 2. Marginal effects of different seed rates on wheat yield.

\begin{tabular}{|c|c|c|c|c|c|c|}
\hline \multirow{3}{*}{$\begin{array}{c}\text { Seed Rate (kg) } \\
50\end{array}$} & \multicolumn{2}{|c|}{ Delta-Method } & \multirow{2}{*}{$\mathbf{t}$} & \multirow{2}{*}{$p>|\mathbf{t}|$} & \multirow{2}{*}{\multicolumn{2}{|c|}{ 95\% Confidence Interval }} \\
\hline & \multirow{2}{*}{$\begin{array}{c}d y d x \\
34.635\end{array}$} & \multirow{2}{*}{$\begin{array}{c}\text { Std. Err } \\
0.37588\end{array}$} & & & & \\
\hline & & & 92.15 & 0.000 & 33.89965 & 35.37706 \\
\hline 100 & 37.321 & 0.25025 & 149.13 & 0.000 & 36.82926 & 37.81289 \\
\hline 150 & 40.004 & 0.25237 & 158.52 & 0.000 & 39.50783 & 40.49977 \\
\hline 200 & 42.246 & 0.75394 & 56.03 & 0.000 & 40.76464 & 43.72809 \\
\hline 250 & 38.733 & 0.37375 & 103.63 & 0.000 & 37.99811 & 39.46745 \\
\hline 300 & 38.480 & 0.48983 & 78.56 & 0.000 & 37.51762 & 39.44294 \\
\hline
\end{tabular}

\subsection{Yield and Economic Effects of Seed Recycling}

One important finding of this study is the practice of seed recycling. The study respondents were asked whether they do recycle wheat seeds or not and how often they do recycle seeds. A good section of the farmers (about 72.89\%) considered in the study does not recycle seed beyond what is recommended (Table 1). Yet, it must be noted that about $27.11 \%$ of the study respondents have recycled seed. Studies in Ethiopia and Tanzania indicated that farmers often used obsolete or old varieties whose seeds are recycled. In Ethiopia, about $76 \%$ and $10 \%$ of the farmers grew modern bread wheat varieties and obsolete varieties, respectively. Several studies also indicated widespread seed recycling practices [19,25-27]. 
This study also solicited the reasons for the existing seed recycling practices. Appendix A Table A4 summarizes the distribution of farmers in terms of their seed recycling practice and reasons for seed recycling. Expensive prices, problems of timely seed supply, and supply shortage have been the most frequently cited reasons for seed recycling. Furthermore, during the FGD, participants mentioned that they see no noticeable difference in yield and other desirable qualities between non-recycled and recycled seeds if the recycling is made only once or twice. Not all studies indeed show a better yield advantage for certified seed over farmer saved seed. Proper seed production and seed saving practices, maintaining a seed free from contamination and varietal purity affect the yield differences significantly [3,28]. Farmers also indicated that the application of different coping mechanisms in times of seed supply shortage and higher seed prices. One important reported strategy was cleaning and saving seed from the existing production to be used in the coming production. Thus, seed recycling in the study area has been practiced as a seed shortage handling and cost reduction strategy. Farmers complain about the expensive price of CBWS and use it as an excuse for seed recycling. However, from findings of the cost-benefit analysis presented in Appendix A, Table A2, one can easily learn that these same farmers still incur costs well above the price of the certified seed. This is mainly because the magnitude of recycled seed rate has been so high, which is above equivalent to the costs incurred in using unrecycled CBWS. However, it must be noted that recycled seeds are cheaper and can be easily obtained informally from friends, relatives, neighbors, and consequently, it may encourage farmers to apply higher seed rates.

The cost-benefit analysis was used to assess the economic impact of seed recycling. The prevailing domestic market price was adopted to calculate the costs and benefits of seed recycling. The cost-benefit analysis is concerned with two important issues. One is costs reduced in the production of goods and services. The second is income increased as a result of the marketing of goods and services. In this study, the cost reduced as a result of seed recycling practice made at the expense of using fresh and unrecycled certified seed was calculated, followed by the income gained as a result of using fresh and unrecycled certified seed at the expense of recycled seed. During the 2019/20 cropping season, the unit cost of $100 \mathrm{~kg}$ of certified unrecycled and recycled bread wheat seeds were 2300 and 1800 Ethiopian Birr (ETB), respectively. Farmers that used unrecycled and fresh certified seeds had a mean seed rate of $169.2835 \mathrm{~kg} \mathrm{ha}^{-1}$ against a mean seed rate of $263.6364 \mathrm{~kg} \mathrm{ha}^{-1}$ in a one-time recycled seed (Appendix A Table A2). The cost reduction (CR) as a result of using a one-time recycled seed at the expense of unrecycled certified seed could be equated as follows:

$$
\mathrm{CR}=\frac{\mathrm{A} 1 \times \mathrm{B} 2}{100}-\mathrm{C} 1
$$

where $\mathrm{CR}=$ is cost reduction as a result of seed recycling, $\mathrm{A} 1=$ Mean seed rate of the unrecycled seed, B2 = cost of one-time recycled seeds, C1 = total seed cost of unrecycled seeds.

Unrecycled certified seed users, on average, used a seed rate of $169.2835 \mathrm{~kg} \mathrm{ha}^{-1}$ with a total seed cost of 3893.51 ETB. If unrecycled certified seed users have turned into use of the recycled seed, then the total seed cost would have been 3047.10 ETB. Following the formula above, it is clear that farmers can reduce their seed cost per hectare by $846.42 \mathrm{ETB}$ by reverting from the use of unrecycled CBWS to a one-time recycled seed use. Thus, the economic rationale of farmers for seed recycling does hold water in terms of cost reduction. A study by [28] supports this finding. These authors found that farmers in Canada try to reduce production costs without incurring large decreases in yield from their own saved seed from a current crop to use for next year's planting, and it is common practice with most cereal and pulse crops. There could be several explanations behind costs reduced as a result of using recycled seed. The first explanation is lower transaction costs. Unrecycled seeds could be purchased from nearby informal sources at local markets. As a result, no extra transportation costs are incurred. In addition to transaction costs, costs pertinent to chemical treatment, labeling, and packaging do not apply to recycled seeds. However, cost reduction alone is not a guarantee to an economically profitable agricultural business. The economic gains as a result of using the other alternative (unrecycled certified seed 
here) or the economic loss as a result of sticking to an old practice (using recycled seed here) are also critical. This calls for the need to calculate the net income gain of a crop enterprise. The next equation in the cost-benefit analysis is to check whether the economic gains from seed recycling are better than unrecycled seed. The income gained (IG) as a result of using unrecycled certified seed at the expense of recycled seed is calculated using the following formula:

$$
\mathrm{IG}=\frac{\mathrm{D} 2 \times \mathrm{F} 1}{\mathrm{D} 1}-\mathrm{F} 2
$$

where IG is income gained, D2 is the mean yield of recycled seed, F1 is mean income from unrecycled seed, D1 is mean yield of unrecycled seed, and F2 is mean income from the recycled seed.

Following the formula above and based on the numerical figures presented in Appendix A, Table A2, the use of fresh and unrecycled CBWS was associated with a higher yield (4044 $\mathrm{kg} \mathrm{ha}^{-1}$ ) and higher market prices (1950 Ethiopian Birr). Similarly, a one-time seed recycling is associated with a lower yield $\left(3333 \mathrm{~kg} \mathrm{ha}^{-1}\right)$ and market prices (1800 Ethiopian Birr). Thus, the average income per hectare given the price of a one-time recycled is $60,823.62 \mathrm{ETB}$. However, a farmer reverting to use fresh and unrecycled seed receive an annual income of $65,892.26$ ETB per hectare. This means that the use of fresh and unrecycled CBWS leads to an economic gain of 5068.635 ETB than a one-time recycled seed. The net income per hectare associated with the use of unrecycled CBWS and a one-time recycled wheat seed was 74,968.58 ETB and 56,078.16 ETB, respectively (Appendix A Table A2). This implies that the use of fresh and unrecycled CBWS ends up in a net income gain of $18,890.42$ ETB per hectare than a one-time recycled seed. To sum up, the results of the cost-benefit analysis made clear that farmers can reduce their seed costs through seed recycling, but their yields and net income can be best improved by using unrecycled CBWS.

Several authors highly suggested that farmers should use unrecycled certified seeds as continuous recycling reduces crop yield $[15,19,29]$. The finding in this study, too, is quite in agreement with these authors. On average, the mean productivity of unrecycled wheat seed users was the highest (Table 3). This highest wheat yield per hectare could be attributed to the yield superiority of the fresh and unrecycled wheat seed. As it can be learned from the above table, on average, a one-time and a twice seed recycling cause a 665 and $711 \mathrm{~kg} \mathrm{ha}^{-1}$ wheat yield decline as compared to the unrecycled certified seed. Here it is worthy of mentioning that the average yield difference between farmers, who recycle once and twice, was not conspicuous. This indicates the fact that the magnitude of yield loss as a result of recycling remains insignificant irrespective of recycling frequency. It signifies the need to rely heavily on fresh and unrecycled CBWS. Nonetheless, during the FGD, farmers opined that a one-time or twice recycling did not cause noticeable yield reduction. Yet, $[14,25]$ reported that fresh certified seeds increase productivity and farmer's efficiency in comparison to frequently recycled seeds. The productivity and efficiency gains indicate that promoting fresh certified wheat seeds has the potential to raise production using the available improved seed technologies at the most efficiency. The finding in this study thus calls for an intensive extension campaign and field-based demonstration to convince farmers of the yield losses as a result of seed recycling. Such a significant yield difference is not expected between fresh certified seed and a one-time seed recycling for self-pollinated crops. The marked difference in yield could, therefore, be attributed to the quality of the seed as indicated by inappropriate seed rate, seed counterfeiting, and unwise planting method [30].

Table 3. Distribution of average productivity and seed recycling.

\begin{tabular}{ccccccc}
\hline \multirow{2}{*}{ Seed Recycling Frequency } & \multirow{2}{*}{ Obs. } & \multicolumn{2}{c}{ Productivity $\left(\mathbf{Q t ~ h a}^{-\mathbf{1}}\right)$} & \multicolumn{2}{c}{ Seed Rate (kg ha $^{-\mathbf{1})}$} \\
\cline { 3 - 6 } & & Mean & Std. Dev & Mean & Std. Dev. \\
\hline Unrecycled & 328 & 40.4421 & 4.9718 & 169.2835 & 66.96013 \\
Recycled once & 110 & 33.7909 & 4.6730 & 263.6364 & 129.0241 \\
Recycled twice and above & 12 & 33.3333 & 7.3278 & 245.8333 & 130.0495 \\
\hline Total & 450 & 38.6267 & 5.7883 & 194.3889 & 97.09256 \\
\hline
\end{tabular}

Source: own calculations (2020). 


\section{Conclusions and Recommendation}

\subsection{Conclusions}

The proportion of farmers that uses a seed rate within the recommended seed rate, above the recommended and below the recommended seed rates were found to be $47.11 \%$, $48 \%$, and $4.89 \%$, respectively. One important finding of this study was the practice of seed recycling. In this regard, one can deduce that about $72.89 \%$ of the farmers in the study area do not recycle seed. Unrecycled seeds were associated with mean productivity of $4044 \mathrm{~kg} \mathrm{ha}^{-1}$, while seeds that were recycled once and more than once were associated with mean productivity of 3379 and $3333 \mathrm{~kg} \mathrm{ha}^{-1}$. This implies that seed recycling, on average, causes $665 \mathrm{~kg}$ yields loss per hectare. A regression coefficient was calculated using the generalized linear model to investigate the effect of the seed rate applied by farmers on wheat productivity. Keeping other factors constant, the result indicated that a $1 \mathrm{~kg}$ increase in seed rate is associated with a 0.054 unit increase in wheat productivity (Appendix A Table A1). From the dose-response relationship, one could learn that the maximum yield was associated with a seed rate of $200 \mathrm{~kg} \mathrm{ha}^{-1}$, which is higher than the recommended seed rate by $50 \mathrm{~kg} \mathrm{ha}^{-1}$. Thus, one can rightly conclude that there exists an opportunity of increasing wheat productivity by adding an extra seed rate of up to $50 \mathrm{~kg} \mathrm{ha}^{-1}$ exists. However, it also has to be noted that any increase in seed rate beyond the optimum found here has led farmers to diminishing productivity. The average wheat productivity associated with farmers, who applied seed rates as per the recommendation, below the recommendation, and above the recommendation were 4037,4036 and $3674 \mathrm{~kg} \mathrm{ha}^{-1}$, respectively. The use of fresh and unrecycled CBWS ends up in a net income gain of 18,890.42 ETB per hectare than a one-time recycled seed. To sum up, the results of the cost-benefit analysis made clear that farmers can reduce their seed costs through seed recycling, but their yields and net income can be best improved by using unrecycled CBWS.

\subsection{Recommendations}

The researcher strongly believes that upon the implementation of the suggestions made here, proper seed rate use will be enhanced. Moreover, the researcher is strongly convinced that these recommendations can be used by farmers, extension agents, development practitioners, policymakers, and other stakeholders involved in wheat production in their efforts to improve wheat productivity. The following are the most important recommendations made based on the findings of the study discussed above.

- Though cost reduction and high seed prices are frequently reported as main factors for seed recycling, the cost-benefit analysis indicated that the use of unrecycled certified seed leads to better economic gains than recycled seeds. Therefore, this study recommends strategies that will encourage the use of fresh and unrecycled certified seeds. Moreover, agricultural credit schemes and price subsidies geared towards helping farmers use unrecycled certified are recommended as key strategies to reduce economically wasteful recycling practices. Implementation of these recommendations is expected to bring multiple benefits. First, it will raise farmer's productivity, income, and food security. Second, seed scientists, seed producers, and other individuals and institutions will benefit the most from their research and innovations. This profit could also be reinvested for more research and development efforts. Third, agro-processing could be enhanced that may increase government revenue and the creation of wider employment opportunities;

- Seed recycling practices have caused yield loss as compared to the non-recycled seeds. Therefore, ensuring the supply of fresh certified seeds is highly recommended. This could be achieved through encouraging seed parastatals, establishing new seed production and marketing cooperatives, and encouraging the existing ones;

- Wheat varietal diversity in the study area is found to be very low. This study, therefore, strongly recommends varietal diversification through the promotion of different varieties in the study areas instead of relying on one variety; 
- Grain yield maximization was the most important reason to use seed rates beyond the recommendation. The evidence from the existing seed rate application of the farmers proved that a higher seed rate of up to $50 \mathrm{~kg} \mathrm{ha}^{-1}$ above the existing recommendation was associated with the highest yield per hectare. Thus, this study strongly suggests that the MoA, agricultural research institutes, and other stakeholders undertake location-specific seed rate trials and validations to keep or modify the existing seed rate application;

- This study has several significant implications for future research efforts that further contribute to the yield effects of plot-level seed rate and seed recycling practices. Thus, research efforts in the following thematic areas will enrich the existing discussions and knowledge as far as the yield effects of seed rate and seed recycling practices are concerned;

- The use of time-series data will provide clear evidence about the yield effects of plot-level seed rates and seed recycling practices of CBWS on a temporal basis;

- The yield effects of wheat seed rates and seed recycling practices for different wheat varieties in different socio-economic settings, weather conditions, and spatial arrangements should be investigated.

Author Contributions: Y.E. generated the idea and study design, collected data, carried out data analysis and writeup. B.A. and Z.B. provided constructive suggestions, statistical assistance, read, edit and revised and shape the manuscript. All authors have read and agreed to the published version of the manuscript.

Funding: This research received no external funding.

Data Availability Statement: The data used to support the findings of this study are available from the corresponding author upon request.

Acknowledgments: The authors of the study want to acknowledge farmers, who devoted their precious time during the interview process, the FGDs, and the KIIs. We also want to extend our gratitude to extension workers and district experts involved in data collection and supervision businesses. We also kindly appreciate the Ministry of Science and Higher Education of the Federal Democratic Republic of Ethiopia and Debre Markos University for their budget support.

Conflicts of Interest: The authors declare no conflict of interest.

\section{Appendix A}

Table A1. Effect of seed dose on wheat productivity.

\begin{tabular}{cccccc}
\hline Source & SS & df & MS & & \\
\hline Model & 4321.22144 & 1 & 4321.22144 & & \\
Residual & $10,722.0586$ & 448 & 23.9331664 & & \\
Total & & 449 & 33.5039644 & & \\
\hline Productivity & Coef. & Std. Err & $\mathbf{t}$ & $\mathbf{t} \mathbf{~}$ & $0.05 \%$ Conf. Interval] \\
\hline Seed_dose & 0.0536544 & 0.003993 & 13.44 & 0.045807 & 0.0615018 \\
_Cons & 31.95563 & 0.5474157 & 58.38 & 30.87981 & 33.03145 \\
\hline
\end{tabular}

Scheme 2020. Number of obs $=450$. Root MSE $=4.8922$. F $(1,448)=180.55$. R-squared $=0.2873$. Prob $>F=0.0000$. Adjusted R-squared $=0.2857$.

Table A2. Cost-benefit analysis of recycled and non-recycled seeds $(n=450)$.

\begin{tabular}{|c|c|c|c|c|c|c|c|c|}
\hline $\begin{array}{c}\text { Seed } \\
\text { Recycling } \\
\text { Frequency }\end{array}$ & Obs. & $\begin{array}{c}\text { Mean Seed } \\
\left.\text { Rate (kg ha }{ }^{-1}\right) \\
\text { (A) }\end{array}$ & 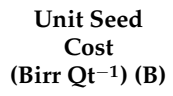 & $\begin{array}{l}\text { Total Seed Cost } \\
\text { (Birr Ha } \text { Ha }^{-1} \\
\text { (C) }\end{array}$ & $\begin{array}{c}\text { Yield } \\
\text { (Qt ha-1) } \\
\text { (D) }\end{array}$ & $\begin{array}{l}\text { Unit Selling } \\
\text { Price } \\
\left(\text { Birr } \mathbf{t}^{-1}\right)(\mathrm{E})\end{array}$ & $\begin{array}{l}\text { Mean Income } \\
\left(\text { Birr Ha }^{-1}\right)(F)\end{array}$ & $\begin{array}{l}\text { Net Income } \\
\left(\text { Birr Ha }^{-1} \text { ) }\right. \\
\text { (G) }\end{array}$ \\
\hline \multirow{2}{*}{$\begin{array}{l}\text { 1. Unrecycled } \\
\text { 2. Recycled } \\
\text { once }\end{array}$} & $328(72.89)$ & 169.2835 & 2300 & 3893.52 & 40.4421 & 1950 & $78,862.095$ & $74,968.575$ \\
\hline & $110(24.44)$ & 263.6364 & 1800 & 4745.46 & 33.7909 & 1800 & $60,823.62$ & $56,078.16$ \\
\hline $\begin{array}{l}\text { 3. Recycled } \\
\text { twice }\end{array}$ & $12(2.67)$ & 245.8333 & 1800 & 4424.999 & 33.3333 & 1800 & $59,999.94$ & $55,574.991$ \\
\hline
\end{tabular}


Table A3. Frequency distribution of respondents by seed source $(n=450)$.

\begin{tabular}{cccc}
\hline Seed Sources & Frequency & Percent & Cumulative \\
\hline Farmers saved seed (informal sources) & 42 & 9.33 & 9.33 \\
Amhara Seed Enterprise & 328 & 72.89 & 82.22 \\
Research and academic institutions & 11 & 2.44 & 84.67 \\
Cooperatives & 69 & 15.33 & 100.00 \\
\hline Total & 450 & 100 & \\
\hline
\end{tabular}

Source: own calculations (2020).

Table A4. Status and reasons for seed recycling $(n=450)$.

\begin{tabular}{cccc}
\hline Status and Reasons for Seed Recycling & Frequency & Percent & Cumulative \\
\hline I do not recycle seed & 328 & 72.89 & 72.89 \\
Cost reduction & 61 & 13.56 & 86.44 \\
Expensive fresh seed & 27 & 6.00 & 92.44 \\
Timely availability and supply shortage & 19 & 4.22 & 96.67 \\
No yield difference & 15 & 3.33 & 100 \\
\hline Total & 450 & 100 & \\
\hline
\end{tabular}

Source: own calculations (2020).

\section{References}

1. Mango, N.; Makate, C.; Tamene, L.; Mponela, P.; Ndengu, G. Impact of the adoption of conservation practices on cereal consumption in a maize-based farming system in the Chinyanja Triangle, Southern Africa. Sustain. Future 2020, 2. [CrossRef]

2. Louwaars, N.P.L.; De Boef, W.S. Integrated seed sector development in Africa: A conceptual framework for creating coherence between practices, programs, and policies. J. Crop Improv. 2012, 26, 39-59. [CrossRef]

3. Zecevic, V.; Boskovic, J.; Knezevic, D.; Micanovic, D. Effect of seeding rate on grain quality of winter wheat. Chil. J. Agric. 2014, 74, 23-28. [CrossRef]

4. Krishna, V.V.; Spielman, D.J.; Veettil, P.C.; Ghimire, S. An Empirical Examination of the Dynamics of Varietal Turnover in Indian Wheat. 2014. IFPRI Discussion Paper 01336. Available online: https:/ / ssrn.com/abstract=2417342 (accessed on 30 January 2020).

5. Lollato, R.P.; Ruiz Diaz, D.A.; De Wolf, E.; Knapp, M.; Peterson, D.E. Agronomic practices for reducing wheat yield gaps: A quantitative appraisal of progressive producers. Crop Sci. 2019, 59, 333. [CrossRef]

6. Vandercasteelen, J.; Dereje, M.; Minten, B.; Taffesse, A.S. Scaling-up adoption of improved technologies: The impact of the promotion of row planting on farmers' tef yields in Ethiopia. LICOS-Discuss. Pap. Ser. 2013, 344, 1-25. Available online: http:/ / www.econ.kuleuven.be/licos (accessed on 1 July 2019).

7. Ritz, C.; Baty, F.; Streibig, J.C.; Gerhard, D. Dose-Response Analysis Using R. PLoS ONE 2015, 10, e0146021. [CrossRef]

8. Van der Vliet, L.; Ritz, C. Statistics for Analyzing Ecotoxicity Test Data. In Encyclopedia of Aquatic Ecotoxicology; Férard, J., Blaise, C., Eds.; Springer: New York, NY, USA, 2013; pp. 1081-1096.

9. Mehring, G.H. Determining Optimum Seeding Rates for Diverse Hard Red Spring Wheat (Triticum aestivum L.) Cultivars; North Dakota State University: Fargo, ND, USA, 2016.

10. MoA (Ministry of Agriculture of the Federal Democratic Republic of Ethiopia). Technological Package for Wheat Production: A Training Manual for Development Practitioners; MoA: Addis Ababa, Ethiopia, 2015.

11. Yamane, T. Statistics: An Introductory Analysis, 2nd ed.; Harper and Row: New York, NY, USA, 2015.

12. Teshome, A.; Abate, E. Wheat Technologies from Where to Where? The Case of East Gojam Zone of Amhara Region, Ethiopia. J. Agric. Econ. Dev. 2013, 2, 226-236. Available online: http://academeresearchjournals.org/journal/jaedISSN2327-3151 (accessed on 29 March 2021).

13. Bishaw, Z.; Struik, P.C.; Van Gastel, A.J.G. Assessment of on-farm diversity of wheat varieties and land-races: Evidence from farmer's field in Ethiopia. Afr. J. Agric. Res. 2014, 9, 2948-2963.

14. Furtas, R. Overview of Certified Seed and Farmer Saved Seed. In An Updated Version of External Release by the Economic and Competitiveness Branch of the Alberta Government; Economics and Competitiveness Branch, Economics Section, Alberta Government: Stettler, AB, Canada, 2016.

15. Bonny, S. Taking stock of the genetically modified seed sector worldwide: Market, stakeholders, and prices. Food Secur. 2014, 6, 525-540. [CrossRef]

16. Tiruneh, S.; Yigesu, A.Y.; Bishaw, Z. Measuring the effectiveness of extension innovations for out scaling agricultural technologies. Afr. J. Agric. Sci. Technol. 2015, 3, 316-326.

17. Bishaw, Z.; Atilaw, A. Enhancing Agricultural Sector Development in Ethiopia: The Role of Research and Seed Sector. Ethiop. J. Agric. Sci. 2016, 27, 101-130. 
18. Gebre, G.G.; Isoda, H.; Rahut, D.B.; Amekawa, Y.; Nomura, H. Gender differences in the adoption of agricultural technology: The case of improved maize varieties in southern Ethiopia. Women's Stud. Int. Forum 2019, 76, 102264. [CrossRef]

19. Bezabih, T. Study on Intensity and Adoption of Improved Wheat Varieties and Associated Agronomic Practices in Kaffa Zone, the Case of Gesha Woreda. In A Thesis Submitted in Partial Fulfillment of the Requirements of MA Degree in Rural Development; Indira Gandhi National Open University (IGNOU): Delhi, India, 2012.

20. Abboye, A.D.; Teto, A.M. The response of Seed Rates and Row Spacing on Growth, Yield and Yield Components of Wheat (Triticum aestivum L.) Crop. J. Nat. Sci. Res. 2020, 10. [CrossRef]

21. Abate, G.T.; Bernard, T.; de Brauw, A.; Minot, N. The Impact of the Use of New Technologies on Farmers Wheat Yield in Ethiopia: Evidence from a Randomized Control Trial. Agric. Econ. 2018, 49, 409-421. [CrossRef]

22. Anteneh, A.; Asrat, D. Wheat Production and Marketing in Ethiopia: A Review Study. Cogent Food Agric. 2020, 6, 1778893. [CrossRef]

23. Okusaa, C. Seed Replacement Rates and Its Impact on Annual Yield Growth of the Kisumu District. In A Thesis Submitted to Jomo Kenyatta University of Agriculture and Technology; Kenyatta University of Agriculture and Technology: Nairobi, Kenya, 2017.

24. Tigabu, R.; Asfaw, F. Effects of Seed Rate and Row Spacing on Yield and Yield Components of Bread Wheat (Triticum aestivum L.) in Dalbo Awtaru Woreda, Wolaita Zone, Southern Ethiopia. J. Biol. Agric. Healthc. 2016, 6, 58-67.

25. Mideksa, T.; Letta, T.; Bayisa, T.; Abinasa, M.; Tilahun, A.; Hundie, B.; Alemu, W.; Abera, M. Bread Wheat Varietal Development and Release in Southeastern Highlands of Ethiopia. Am. J. Biol. Environ. Stat. 2018, 4, 15-19. [CrossRef]

26. Tesfaye, S.; Bedada, B.; Mesay, Y. Impact of improved wheat technology adoption on productivity and income in Ethiopia. Afr. Crop Sci. J. 2016, 24, 127. [CrossRef]

27. Bishaw, Z.; Struik, P.C.; van Gastel, A.J.G. Wheat and barley seed system in Syria: Farmer's varietal perceptions, seed sources, and seed management. Int. J. Plant Prod. 2011, 5, 323-347.

28. Clayton, G.W.; Brandt, S.; Johnson, E.N.; O’Donovan, J.T.; Harker, K.N.; Blackshaw, R.E.; Smith, E.G.; Kutcher, H.R.; Vera, C.; Hartman, M. Comparison of Certified and Farm-Saved Seed on Yield and Quality Characteristics of Canola. Agron. J. 2009, 101, 1581-1588. [CrossRef]

29. ATA (Agricultural Transformation Agency). A Training Manual on Cereal Production; ATA (Agricultural Transformation Agency): Addis Ababa, Ethiopia, 2015.

30. Tsegaye, D. Profitability of Contractual Bread Wheat Seed Production in Mecha District of Amhara Region, Ethiopia. J. Central Eur. Agric. 2012, 13, 142-149. [CrossRef] 